\title{
Hubungan Kepatuhan Minum Tablet Fe dengan Kejadian Anemia (Hb) pada Remaja Putri Di SMP Negeri 1 Tapen Kabupaten Bondowoso
}

\author{
Kristiyan Adi Putra1, Zainal Munir2, Wiwin Nur Siam ${ }^{3}$ \\ 1Puskesmas Tapen Bondowoso, email : kriezadi13@gmail.com \\ 2 Universitas Nurul Jadid, email: zainalmunirnj@gmail.com \\ ${ }^{3}$ RSUD. Dr. Koesnadi Bondowoso, email: winnursiam@gmail.com
}

\begin{abstract}
Anemia often occurs in young women because in adolescence there has been rapid growth into the age of puberty including red blood cells will increase. In addition, in young women, menstrual cycles begin to occur that will release blood from the body with a considerable amount. One effort that can be done is to consume Fe tablets. The research design is a quantitative method in the form of Cross Sectional Design. The study was conducted on Class VII Adolescent Girls in Junior High School 1 Tapen Tapen, Bondowoso in May 2019 with a sample of 33 respondents. The measuring instrument used was a questionnaire sheet which then carried out the Spearman Rho analysis test with a significance level of $p \leq 0.05$. The results obtained p-value 0.007 ( $P \leq 0.05)$. So Ho was rejected and $H 1$ was accepted, so there was a correlation between the Compliance of consumption $\mathrm{Fe}$ tablets with the incidence of Anemia in Class VII Adolescent Girls in Junior High School 1 Tapen, Tapen, Bondowoso. There is a need for counseling on the importance of consumption of Fe tablets and collaboration with teachers regarding the consumption of Fe tablets.
\end{abstract}

Keywords: Fe Tablet Consumption, Compliance, Incidence of Anemia

\section{Abstrak}

Anemia sering terjadi pada remaja putri karena pada masa remaja telah terjadi pertumbuhan cepat memasuki usia pubertas termasuk sel-sel darah merah akan meningkat. Selain itu pada remaja putri mulai terjadi keteraturan siklus menstruasi yang akan mengeluarkan darah dari tubuh dengan jumlah yang cukup banyak. Salah satu upaya yang dapat dilakukan adalah dengan konsumsi tablet Fe. Desain penelitian metode kuantitatif bentuk Cross Sectional Design. Penelitian dilakukan pada Remaja Putri Kelas VII di SMP Negeri 1 Tapen Kecamatan Tapen Kabupaten Bondowoso pada bulan Mei 2019 dengan jumlah sampel 33 responden. Alat ukur yang digunakan adalah lembar kuisioner yang selanjutnya dilakukan uji analisa Spearman Rho dengan derajat kemaknaan $p \leq 0,05$. Hasil penelitian didapatkan $p$-value 0,007 $(P \leq 0,05)$. Maka Ho ditolak dan H1 diterima maka, ada hubungan Kepatuhan Minum Tablet Fe dengan Kejadian Anemia Pada Remaja Putri Kelas VII di SMP Negeri 1 Tapen Kecamatan Tapen Kabupaten Bondowoso. Diperlukan adanya penyuluhan tentang pentingnya konsumsi tablet $\mathrm{Fe}$ dan kolaborasi dengan guru terkait pemberian konsumsi tablet Fe.

Kata Kunci : Konsumsi Tablet Fe, Kepatuhan, Kejadian Anemia 


\section{Pendahuluan}

Kejadian anemia di negara Indonesia juga masih merupakan masalah keadaan masyarakat yang utama untuk ditangani. Pemerintah telah melakukan upaya upaya perbaikan gizi masyarakat secara intensif untuk menurunkan pravalensi anemia, namun sampai saat ini anemia masih merupakan masalah utama (Kementrian Kesehatan RI, 2013)

Anemia merupakan salah satu masalah kesehatan memiliki angka kejadian cukup tinggi di dunia dengan angka pravalensi mencapai $40-48 \%$ yang tersebar di seluruh dunia. Kejadian anemia banyak terjadi di negara berkembang dengan angka kejadian 3-4 kali lebih besar dibandingkan negara maju. Anemia tertinggi di dunia berada di bagian Asia Selatan, Asia tengah, dan Asia Barat. Wanita muda memiliki risiko yang lebih tinggi menderita anemia dibandingkan dengan laki-laki muda karena wanita sering mengalami pendarahan menstruasi yang teratur (Proverawati dan Wati, 2011).

Remaja putri merupakan salah satu kelompok yang rawan menderita anemia. Di Indonesia, prevalensi anemia masih cukup tinggi. Penyebab utama anemia gizi pada remaja putri adalah karena kurangnya asupan zat gizi melalui makanan, sementara kebutuhan zat besi relative tinggi untuk kebutuhan dan menstruasi. Kehilangan zat besi diatas rata - rata dapat terjadi pada remaja putri dengan pola haid yang lebih banyak dan waktunya lebih panjang.

kebutuhan

Meningkatnya

bila diiringi kurangnya asupan zat besi dapat mengakibatkan remaja putri rawan terhadap rendahnya kadar haemoglobin. (Krummer, Kris, 2006)

Menurut Survei Nasional Kesehatan Keluarga (SNKK) menyebutkan bahwa angka kejadian anemia sebanyak 15-24 tahun 18,4\%. Berdasarkan data Depkes RI (2012) prevalensi anemia defisiensi besi di Indonesia pada balita sebesar $40,5 \%$, ibu hamil sebesar 50,5\%, ibu nifas sebesar $45,1 \%$, remaja putri usia 10-18 tahun sebesar $57,1 \%$, dan pada Wanita Usia Subur (WUS) usia 19-45 tahun sebesar 39,5\%. Berdasarkan kelompok usia tersebut yang memiliki risiko paling besar menderita anemia adalah remaja putri usia 10-18 tahun (Departemen Kesehatan RI, 2012).

Salah satu penyebab anemia pada remaja putri menstruasi yang bisa terjadi dalam rentang usia 10-16 tahun atau pada masa awal remaja, Volume darah yamg keluar saat menstruasi mengakibatkan kehilangan zat besi sebanyak 12$15 \mathrm{mg}$ per bulan atau $0,4-0,5 \mathrm{mg}$ per hari (Retno, 2017). Pada saat menstruasi wanita tidak hanya mengalami kehilangan zat besi tetapi juga mengalami kehilangan basal, jadi bila ditotal wanita perhari mengalami kehilangan zat besi sebanyak 1,25 mg. Volume darah yang keluar setiap bulannya berkisar 30-50 cc. Kondisi tersebut menyebabkan wanita mengalami anemia. Anemia ditandai dengan rendahnya konsentrasi 
hemoglobin $(\mathrm{Hb})$ atau hematokrit dari nilai ambang batas yang disebabkan oleh rendahnya produksi sel darah merah (eritrosit) dan $\mathrm{Hb}$, meningkatnya kerusakan eritrosit atau kehilangan darah yang berlebihan (Kristianti, 2014).

Untuk mengantisipasi anemia zat besi adalah dengan cara pemberian tablet zat besi, pendidikan dan upaya yang ada kaitannya dengan peningkatan asupan zat besi melalui makanan, pengawasan penyakit infeksi dan fortifikasi makanan pokok dengan zat besi (Arisman, 2009). Penelitian Wahyuningsih (2012) menyebutkan secara statistik terdapat hubungan yang signifikan anemia dengan siklus menstruasi pada remaja dengan pemeberian suplementasi besi atau tablet $\mathrm{Fe}$ menunjukkan bahwa terdapat prevalensi anemia sebelum suplementasi sebesar $25.1 \%$ dan menurun menjadi $\quad 15.3 \% \quad$ setelah suplementasi (Wahyuningsih, 2012).

Berdasarkan studi pendahuluan yang peneliti laksanakan di SMP Negeri 1 Tapen Kecamatan Tapen Kabupaten Bondowoso, berdasarkan wawancara dengan guru-guru bahwa hampir setiap bulan banyak siswa putri mengeluh pusing, sakit perut, sampai wajahnya pucat saat menstruasi, remaja putri yang berisiko anemia pada remaja putri kelas VII yaitu sebesar 33 orang.

Didukung dengan data dari Dinas Kesehatan Bondowoso pada tahun 2018 bahwa terdapat
$39,2 \%$ remaja putri yang berisiko anemia (Dinas Kesehatan Kabupaten Bondowoso, 2018). Dikalangan remaja yang memiliki kesadaran rendah dalam memperhatikan makanan yang masuk dalam tubuh, dirasa perlu menambah upaya untuk menambah upaya agar zat besi yang kurang dapat terpenuhi setiap harinya. Namun saat ini masih banyak remaja putri yang tidak patuh terhadap konsumsi $\mathrm{Fe}$ disebabkan banyak faktor, seperti malas dan efek samping yang sering dirasakan yang dirasakan setelah minum $\mathrm{Fe}$.

Kepatuhan adalah suatu perubahan perilaku dari perilaku yang tidak menaati peraturan. Masalah kepatuhan merupakan kendala suplemtasi besi harian, karena itu untuk menjaga kepatuhan konsumsi supleman besi dapat diadakan dengan upaya mengkonsumsi suplemen besi langsung di depan petugas, dengan mengirimkan pesan singkat kepada sampel penelitian (Retno, 2017).

Beberapa

sebelumnya

penelitian bahwa faktor-faktor yang mempengaruhi anemia diantaranya pengetahuan gizi, pola makan dan kepatuhan konsumsi tablet Fe. Hasil penelitian Yuniarti (2015) menyatakan bahwa jika pengetahuan gizi dipadukan dengan pemberian suplementasi besi terhadap remaja putri akan menghasilkan peningkatan kadar hemoglobin yang paling efektif dibandingkan dengan pengetahuan gizi saja atau pemberian suplementasi 
mingguan selama dua belas minggu. Kepatuhan minum tablet $\mathrm{Fe}$ dipengaruhi oleh dua faktor utama,yaitu faktor dari petugas kesehatan dan faktor dari diri sendiri seperti kesadaran dalam mengkonsumsi tablet Fe. Kepatuhan dalam mengkonsumsi tablet $\mathrm{Fe}$ memiliki hubungan yang signifikan dengan peningkatan kadar hemoglobin pada remaja SMP (Yuniarti, dkk., 2015).

$$
\text { Adanya pengaruh }
$$

pemberian tablet $\mathrm{Fe}$ terhadap peningkatan kadar HB menunjukkan bahwa pemberian tablet Fe efektif untuk mencegah terjadinya anemia pada mahasiswi. Menurut Arisman (2009) anemia zat besi dapat dicegah dengan cara pemberian tablet zat besi, terutama melalui makanan. Kepatuhan dalam mengkonsumsi suplementasi zat besi atau pemberian tablet $\mathrm{Fe}$ sangat mempengaruhi perubahan kadar hemoglobin, dimana kadar hemoglobin yang normal maka status anemia juga akan normal, sehingga dapat mencegah dan menanggulangi anemia defisiensi besi (Arisman, 2009)

Tujuan dari penelitian ini (1) mengidentifikasi karakteristik responden berdasarkan (umur, menstruasi pertama, siklus menstruasi dan konsumsi sayuran yang mengandung zat besi); (2) mengidentifikasi kepatuhan minum tablet $\mathrm{Fe}$ anemia pada remaja putri ; (3) mengidentifikasi kejadian Anemia $(\mathrm{Hb})$ pada remaja putri (4) menganalisis Hubungan kepatuhan minum tablet $\mathrm{Fe}$ dengan kejadian anemia $(\mathrm{Hb})$ pada remaja putri di SMP Negeri 1 Tapen Kabupaten Bondowoso.

\section{Metode}

Desain penelitian yang digunakan dalam penelitian ini berjenis penelitian analitik korelational dengan pendekatan penelitian cross sectional. dengan sampel sebanyak 33 responden yang memenuhi kreteria inklusi dengan teknik Purposive Sampling.

Analisis data yang digunakan dalam penelitian ini adalah analisis univariat, analisis bivariat dengan korelasi Spearman's Rho.

\section{Hasil Penelitian}

\section{Karakteristik Responden}

Tabel 1 Distribusi Frekuensi

Karakteristik Responden

\begin{tabular}{lcc}
\hline $\begin{array}{c}\text { Karakteristik } \\
\text { Responden }\end{array}$ & $\mathbf{f}$ & $\mathbf{( \% )}$ \\
\hline Umur & & \\
\hline 12 tahun & 5 & 15.2 \\
13 tahun & 23 & 69.7 \\
14 tahun & 5 & 15.2 \\
\hline Menstruasi Pertama & \\
\hline 9 - 10 tahun & 12 & 36.4 \\
$11-12$ tahun & 14 & 42.4 \\
$13-14$ tahun & 7 & 21.2 \\
\hline $\begin{array}{l}\text { Siklus } \\
\text { Menstruasi }\end{array}$ & \\
\hline $\begin{array}{l}\text { Teratur } \\
\text { Tidak Teratur }\end{array}$ & 13 & 39.4 \\
\hline $\begin{array}{l}\text { Konsumsi Sayuran yang } \\
\text { Mengandung Zat Besi }\end{array}$ \\
\hline $\begin{array}{l}\text { Mengkonsumsi } \\
\text { Tidak } \\
\text { Mengkonsumsi }\end{array}$ & 60.6 \\
\hline
\end{tabular}


Berdasarkan tabel 1 dapat diketahui bahwa dari 33 responden sebagian besar responden berusia 13 tahun sebanyak 69,7\% (23 responden), menstruasi pertama umur 11-12 tahun sebanyak $42,4 \% \quad(14$ responden), siklus menstruasi tidak teratur sebanyak 60,6\% (20 responden), mengkonsumsi sayuran yang mengandung zat besi sebanyak $66,7 \% \quad(22$ responden).

\section{Kepatuhan Konsumsi Tablet} Fe

Tabel 2. Distribusi Frekuensi Responden Berdasarkan Kepatuhan Konsumsi Tablet Fe

\begin{tabular}{ccc}
\hline $\begin{array}{c}\text { Kepatuhan } \\
\text { Konsumsi } \\
\text { Tablet Fe }\end{array}$ & f & \% \\
\hline Patuh & 24 & 72.7 \\
\hline Tidak Patuh & 9 & 27.3 \\
\hline Total & 33 & 100.0 \\
\hline
\end{tabular}

Berdasarkan tabel 2 dapat diketahui bahwa dari 33 responden sebagian besar responden patuh dalam mengkonsumsi tablet $\mathrm{Fe}$ sebanyak 72,7\% (24 responden).

\section{Nilai Hemoglobin (Hb)}

Tabel 3. Distribusi Frekuensi Responden Berdasarkan Nilai Hemoglobin (Hb)

\begin{tabular}{lcc}
\hline \multicolumn{1}{c}{ Nilai Hb (gr/dl) } & $\mathbf{f}$ & $\mathbf{\%}$ \\
\hline Normal $(12-14)$ & 22 & 66.7 \\
Ringan $(11-$ & 7 & 21.2 \\
11,9) & & 12.1 \\
Sedang $(8-10,9)$ & 4 & 0 \\
Berat $(<8)$ & 0 & 100.0 \\
\hline \multicolumn{1}{c}{ Total } & 33 &
\end{tabular}

Berdasarkan tabel 3 dapat
diketahui bahwa dari 33
responden sebagian $\quad$ besar
responden memiliki $\mathrm{Hb}$ yang
normal sebanyak $66,6 \% \quad(22$
responden).

\section{Hubungan Kepatuhan Minum Tablet Fe dengan Kejadian Anemia}

Tabel 4. Hasil Uji Statistik Spearman Rho Hubungan Kepatuhan Minum Tablet Fe dengan Kejadian Anemia

\begin{tabular}{|c|c|c|c|c|c|c|}
\hline \multirow{2}{*}{$\begin{array}{c}\text { Variabel } \\
\text { Kepatuhan minum } \\
\text { tablet } \mathrm{Fe}\end{array}$} & \multicolumn{4}{|c|}{ Nilai Hb } & \multirow[b]{2}{*}{$\begin{array}{c}P \\
\text { value }\end{array}$} & \multirow[b]{2}{*}{$\begin{array}{c}\mathbf{R} \\
\text { hitung }\end{array}$} \\
\hline & $\begin{array}{l}\text { Normal } \\
(12-14)\end{array}$ & $\begin{array}{l}\text { Ringan } \\
(11- \\
11.9)\end{array}$ & $\begin{array}{l}\text { Sedang } \\
(8- \\
10.9)\end{array}$ & $\begin{array}{l}\text { Berat } \\
(<8)\end{array}$ & & \\
\hline Patuh & 19 & 4 & 1 & 0 & 0.007 & 0.005 \\
\hline Tidak patuh & 3 & 3 & 3 & 0 & & \\
\hline
\end{tabular}

Tabel 4 diketahui bahwa hasil analisa statistik dengan uji korelasi Spearman Rho diperoleh nilai $p$-value $0,007 \quad(\mathrm{p}<0,05), \quad$ artinya ada hubungan yang signifikan antara kepatuhan minum tablet Fe dengan kejadian anemia. Sehingga Ho ditolak yang berarti bahwa ada perbedaan atau hipotesa peneliti diterima.
Kekuatan hubungan dalam penelitian ini yaitu 0,464 yang artinya adanya hubungan yang positif dengan kekuatan hubungan sedang. Semakin patuh terhadap konsumsi tablet $\mathrm{Fe}$ maka nilai $\mathrm{Hb}$ akan semakin normal atau baik 


\section{Pembahasan}

\section{Karakteristik Responden}

Hasil penelitian menunjukkan bahwa sebagian besar responden berusia 13 tahun sebanyak 69,7\% (23 responden). Batasan usia remaja menurut WHO (2010) adalah usia 12-24 tahun. Menurut Depkes RI (2008) usia remaja antara 10-19 tahun dan belum kawin. Remaja mempunyai resiko tinggi mengalami anemia karena defesiensi zat besi. Hal ini disebabkan karena pada fase ini remaja mengalami pertumbuhan yang pesat disertai berbagai perubahan hormonal menjelang fase kedewasaan. Remaja membutuhkan sejumlah besar nutrisi terutama zat besi yang di gunakan untuk mengangkut oksigen. Zat besi yang tidak mencukupi memicu terjadinya anemia (Giyanti, 2016).

Peneliti berasumsi bahwa, usia remaja 10-19 tahun merupakan usia pertumbuhan dan perkembangan yang memerlukan energi yang lebih banyak, sehingga diperlukan suplemen tambahan berupa tablet Fe untuk mencegah terjadinya anemia.

Hasil penelitian sebagian besar responden menstruasi pertama umur 11-12 tahun sebanyak 42,4\% (14 responden). Usia menarche umumnya terjadi pada usia 12 sampai 16 tahun, tetapi sering terjadi pada usia 11 tahun. Usia menarche dikatakan cepat bila terjadi pada usia kurang dari 11 tahun, normal terjadi antara usia 11 sampai 14 tahun, dan lambat bila terjadi pada usia lebih dari 14 tahun (Dumilah, Pratiwi dan Sri Utami, 2017).

Penelitian Rupali dan Sanjay (2015) yang menunjukkan tidak ada hubungan antara usia menarche dengan anemia. Sebagian besar siswi mengalami usia menarche yang tergolong normal dan sebagian besar siswi tidak mengalami anemia. Anemia pada remaja disebabkan oleh beberapa faktor diantaranya perdarahan hebat dan menstruasi setiap bulan, kurangnya kadar zat besi dalam tubuh, kekurangan asam folat, vitamin B12, penyakit kronis, penyakit malaria, infeksi cacing tambang, keturunan atau genetik. Peneliti berasumsi bahwa antara menarche dengan kejadian anemia tidak berhubungan karena anemia dapat disebabkan karena perdarahan menstruasi yang banyak dan kurangnya kadar zat besi dalam tubuh.

Sebagian besar responden siklus menstruasi tidak teratur sebanyak $60,6 \% \quad(20$ responden). Hasil penelitian tersebut sesuai dengan penelitian Yamin (2012) yang menunjukkan tidak terdapat hubungan antara siklus menstruasi dengan kejadian anemia dengan remaja putri. Siswi yang memiliki siklus menstruasi teratur juga berkemungkinan memiliki pola makan yang baik dan mengkonsumsi tablet tambah darah yang telah diberikan oleh pihak puskesmas sehingga dapat mengganti zat besi yang hilang saat menstruasi berlangsung (Hidayat, Sunarti, 2015). Berdasarkan uraian diatas peneliti berasumsi bahwa siklus menstruasi siswi tidak berhubungan dengan anemia, karena antara siswa yang memiliki siklus menstruasi teratur dan tidak teratur sama-sama mengkonsumsi tablet tambah darah. Sehingga, dengan mengkonsumsi tambah darah akan mencegah terjadinya anemia.

Sebagian besar mengkonsumsi sayuran yang mengandung zat besi sebanyak $66,7 \%$ (22 responden). Penelitian Sri Utami Arifin, dkk (2013) yang mengungkapkan adanya 
hubungan asupan Zat Besi (Fe) dengan Kadar Hemoglobin. Selama masa pertumbuhan yang cepat, seperti pada bayi, anak, remaja, dan ibu hamil masukan besi sulit membuat keseimbangan positif. Sebagian besar penduduk yang mengalami kekurangan zat besi, terutama di negara yang sedang berkembang termasuk Indonesia, disebabkan oleh sedikitnya asupan makanan yang mengandung zat besi dan rendahnya konsumsi makanan yang mengandung zat gizi lainnya yang mempunyai konstribusi terhadap absobsi dan metabolisme zat besi seperti misalnya vitamin $\mathrm{C}$. Rata-rata remaja tidak menyukai sayur-sayuran dan lebih suka makanan yang instan (Pradanti, dkk, 2015).

Peneliti berasumsi bahwa konsumsi sayuran yang mengandung zat besi juga dapat mempengaruhi nilai $\mathrm{Hb}$. Lebih banyak remaja dalam masa pertumbuhan yang tidak menyukai sayur-sayuran dan cenderung makan makanan yang intan dan junk food.

\section{Kepatuhan Minum Tablet Fe Anemia Pada Remaja Putri}

Berdasarkan hasil penelitian menunjukkan bahwa sebagian besar responden patuh dalam mengkonsumsi tablet $\mathrm{Fe}$ sebanyak $72,7 \%$. Hasil analisa kuisioner menunjukkan bahwa kepatuhan responden yang kurang dalam hal: meminum tablet $\mathrm{Fe}$ dengan teratur tanpa di ingatkan oleh keluarga, keluarga selalu mengingatkan untuk meminum tablet Fe, manfaat meminum tablet $\mathrm{Fe}$, dampak kekurangan zat besi (Fe), efek samping setelah minum tablet Fe. Sedangkan analisa kuisioner kepatuhan responden yang sudah bagus adalah meminum tablet $\mathrm{Fe}$ sesuai dengan dosis yang telah diberikan, tidak menghentikan konsumsi tablet $\mathrm{Fe}$ sebelum waktunya, tidak meminum tablet $\mathrm{Fe}$ dengan kopi, tidak mual setelah minum tablet $\mathrm{Fe}$, tablet $\mathrm{Fe}$ diminum setiap hari.

Faktor yang berpengaruh terhadap kepatuhan adalah pengetahuan responden. Pengetahuan merupakan salah satu faktor predisposing (predisposisi) yang dapat memengaruhi perilaku individu untuk mengonsumsi tablet tambah darah, karena pengetahuan merupakan faktor dominan untuk terbentuknya tindakan seseorang. Pengetahuan merupakan segala informasi yang diterima seseorang dari luar dirinya dan disertai dengan pemahaman terhadap informasi yang didapatkan (Susanti, 2016).

Penelitian ini tidak sejalan dengan penelitian yang dilakukan Budiarni dan Subagio (2012), sebesar $48,2 \%$ subjek tidak mengonsumsi TTD karena rasa yang tidak enak dan bau amis. Sehingga Hanya sedikit subjek yang menyukai karakteristik tablet tambah darah dan patuh untuk mengonsumsinya (Rahmawati, 2012).

Sejalan dengan penelitian tentang hubungan dukungan keluarga dengan kepatuhan konsumsi tablet $\mathrm{Fe}$ di Puskesmas Nanggalo Kecamatan Nanggalo Kota Padang tahun 2015. Hasil penelitian menunjukkan sebanyak 59.4\% responden mendapat dukungan keluarga yang rendah dan $71.9 \%$ responden memiliki kepatuhan konsumsi tablet $\mathrm{Fe}$ yang rendah. Dari uji statistik dapat disimpulkan terdapat hubungan antara dukungan keluarga dengan kepatuhan konsumsi tablet $\mathrm{Fe}(\mathrm{p}<0.05)$. Untuk itu, disarankan kepada perawat atau petugas kesehatan lainnya agar mulai mengajak dan 
mengikutsertakan anggota keluarga (Maisa, 2015).

Sejalan dengan penelitian Susanti (2016) yang menyimpulkan bahwa tingkat kepatuhan konsumsi tablet besi tinggi setelah adanya motivasi yang kuat di sekolah, terlebih ketika suplementasi tersebut dikombinasi dengan sesi pendidikan gizi/konseling bulanan. Beberapa alasan suplemen tidak diminum yang disampaikan subjek antara lain malas/bosan $\quad(29,1 \%)$, tablet rusak/hilang (20,0\%) dan lupa $(19,4 \%)$. Keluhan yang paling banyak disampaikan oleh subjek setelah konsumsi suplemen adalah pusing $(38,8 \%)$, mual/eneg $(34,3 \%)$ dan mudah mengantuk $(21,1 \%)$ (Susanti, 2016).

Remaja putri diharuskan mengkonsumsi Tablet Tambah Darah karena mengalami menstruasi setiap bulan. Tablet Tambah Darah berguna untuk mengganti zat besi yang hilang karena menstruasi dan untuk memenuhi kebutuhan zat besi yang belum tercukupi dari makanan. Zat besi pada remaja putri juga bermanfaat untuk meningkatkan konsentrasi belajar, menjaga kebugaran dan mencegah terjadinya anemia pada calon ibu di masa mendatang (Dieny, 2014).

Peneliti berasumsi

bahwa

kepatuhan

dipengaruhi responden

dapat responden tentang pentingnya konsumsi tablet $\mathrm{Fe}$ dan adanya dukungan yang diberikan oleh orang tua kepada anak untuk minum tablet Fe. Sehingga dapat disimpulkan bahwa, kepatuhan responden dalam mengkonsumsi tablet $\mathrm{Fe}$ bisa dipengaruhi oleh berbagai faktor dan yang terpentingadalah adanya dukungan dari keluarga, guru, dan pengetahuan yang dimiliki oleh responden tentang manfaat konsumsi tablet $\mathrm{Fe}$ dan efeksamping konsumsi tablet Fe.

\section{Kejadian Anemia Pada Anemia Pada Remaja Putri}

Hasil penelitian menunjukkan bahwa sebagian besar responden memiliki $\mathrm{Hb}$ yang normal (12-14 $\mathrm{gr} / \mathrm{dl}) \quad$ sebanyak $\quad 66,6 \% \quad(22$ responden). Nilai $\mathrm{Hb}$ yang sudah normal ini dapat dipengaruhi oleh adanya pemberian informasi terlebih dahulu oleh petugas kesehatan tentang manfaat dan tujuan untuk minum tablet $\mathrm{Fe}$ secara rutin dan dampak yang ditimbulkan jika tidak mengkonsumsi tablet Fe. Sehingga sebagian besar siswa sudah memiliki nilai $\mathrm{Hb}$ yang normal, meskipun ada sebagian kecil yang masih memiliki nilai $\mathrm{Hb}$ yang masih memiliki nilai $\mathrm{Hb}$ sedang (8-10,9 gr/dl) sebanyak $12,1 \%$ (12 responden).

Remaja putri merupakan salah satu kelompok yang rawan menderita anemia. Di Indonesia, prevalensi anemia masih cukup tinggi. Penyebab utama anemia gizi pada remaja putri adalah karena kurangnya asupan zat gizi melalui makanan, sementara kebutuhan zat besi relatif tinggi untuk kebutuhan dan menstruasi. Kehilangan zat besi diatas rata-rata dapat terjadi pada remaja putri dengan pola haid yang lebih banyak dan waktunya lebih panjang (Krummer, 2006).

Meningkatnya kebutuhan bila diiringi kurangnya asupan zat besi dapat mengakibatkan remaja putri rawan terhadap rendahnya kadar hemoglobin. Alasan lain karena remaja putri seringkali menjaga penampilan, keinginan untuk tetap langsing atau kurus sehingga berdiet dan mengurangi makan. Diet yang tidak seimbang dengan kebutuhan zat gizi tubuh akan menyebabkan tubuh kekurangan zat gizi yang penting seperti besi (Arisman, 2009). 
Salah satu penyebab anemia pada remaja putri menstruasi yang bisa terjadi dalam rentang usia 10-16 tahun atau pada masa awal remaja, Volume darah yang keluar saat menstruasi mengakibatkan kehilangan zat besi sebanyak 12-15 mg per bulan atau 0,4-0,5 mg per hari (Retno, 2017). Pada saat menstruasi wanita tidak hanya mengalami kehilangan zat besi tetapi juga mengalami kehilangan basal, jadi bila ditotal wanita perhari mengalami kehilangan zat besi sebanyak 1,25 mg. Volume darah yang keluar setiap bulannya berkisar 30-50 cc. Kondisi tersebut menyebabkan wanita mengalami anemia. Anemia ditandai dengan rendahnya konsentrasi hemoglobin $(\mathrm{Hb})$ atau hematokrit dari nilai ambang batas yang disebabkan oleh rendahnya produksi sel darah merah (eritrosit) dan $\mathrm{Hb}$, meningkatnya kerusakan eritrosit atau kehilangan darah yang berlebihan (Kristianti, 2014).

Untuk mengantisipasi anemia zat besi adalah dengan cara pemberian tablet zat besi, pendidikan dan upaya yang ada kaitannya dengan peningkatan asupan zat besi melalui makanan, pengawasan penyakit infeksi dan fortifikasi makanan pokok dengan zat besi (Arisman, 2009). Penelitian Wahyuningsih (2012) menyebutkan secara statistik terdapat hubungan yang signifikan anemia dengan siklus menstruasi pada remaja dengan pemeberian suplementasi besi atau tablet $\mathrm{Fe}$ menunjukkan bahwa terdapat prevalensi anemia sebelum suplementasi sebesar $25.1 \%$ dan menurun menjadi $15.3 \%$ setelah suplementasi (Wahyuningsih, 2012).

Sejalan dengan penelitian yang dilakukan oleh Cahyaningtyas (2017) menunjukkan bahwa hasil uji statistik didapatkan terdapat pengaruh konsumsi tablet $\mathrm{Fe}$ terhadap peningkatan kadar hemoglobin pada remaja putri di SMA 2 Ngaglik Sleman. Penelitian ini menunjukkan bahwa ada peningkatan kadar hemoglobin setelah mengkonsumsi tablet Fe. Intervensi yang diberikan pada responden dengan mengkonsumsi tablet $\mathrm{Fe}$ sangat membantu untuk menanggulangi anemia zat besi. Adapun faktor yang mempengaruhi peningkatan kadar hemoglobin pada remaja putri yaitu usia, frekuensi mentruasi, status gizi, pola makan, jenis makanan yang dikonsumsi, konsumsi tablet Fe dan aktivitas fisik (Cahyaningtyas, 2017).

Faktor lain yang dapat diketahui dalam mempengaruhi kenaikan kadar hemoglobin yaitu siswi putri mengkonsumsi tablet $\mathrm{Fe}$ yang telah diberikan peneliti selama 1 bulan (30 hari) dan tetap mengkonsumsi selama menstruasi. Hal ini dapat dibuktikan dalam teori yang mengatakan bahwa pemberian tablet $\mathrm{Fe}$ ini kepada remaja putri sangat bermanfaat pada keadaan haid, dikarenakan saat itu bisa terjadi kehilangan besi akibat perdarahan. Karena haid rata-rata mengeluarkan darah $60 \mathrm{ml}$ perbulan yang sama dengan $30 \mathrm{mg}$ besi, sehingga perempuan memerlukan tablet tambah darah satu miligram perhari agar keseimbangan tetap terjaga. Mengkonsumsi tablet $\mathrm{Fe}$ dapat mengobati wanita dan remaja putri yang mengalami anemia, meningkatkan kemampuan belajar, meningkatkan status gizi dan kesehatan remaja (Sani, 2010).

Faktor yang paling berpengaruh terhadap peningkatan kadar $\mathrm{Hb}$ pada penelitian Susanti adalah status $\mathrm{Hb}$ awal. Banyak studi menunjukkan bahwa subjek yang anemia akan lebih responsif di dalam peningkatan hemoglobin, cadangan besi yang 
kurang (depleted) dapat menyebabkan perbaikan biomarker yang lebih baik dibandingkan subjek yang tidak mengalami deplesi besi. Hasil studi eksperimental mengenai suplementasi besi menunjukkan bahwa perubahan kadar $\mathrm{Hb}$ hanya dipengaruhi oleh $\mathrm{Hb}$ awal (Susanti, 2016).

Peneliti berasumsi bahwa nilai $\mathrm{Hb}$ dapat dipengaruhi oleh kurangnya kesadaran dalam mengkonsumsi tablet $\mathrm{Fe}$ ataupun kurangnya asupan makanan yang mengandung zat besi, karena anak remaja lebih banyak yang tidak menyukai sayuran dan lebih banyak makanan instan atau siap saji yang dikonsumsi. Faktor lain yang juga mempengaruhi adalah adanya dukungan kelarga yang diberikan masih kurang, dikarenakan ada orang tua yang bekerja dan tidak memperhatikan anaknya, sehingga remaja sering lupa untuk mengkonsumsi tablet $\mathrm{Fe}$ secara mandiri. Faktor yang sangat mendukung adalah dukungan dari guru dan pengetahuan remaja putri tentang pentingnya konsumsi tablet Fe.

\section{Sehingga dapat disimpulkan} bahwa peningkatan $\mathrm{Hb}$ dapat dipengaruhi oleh banyak faktor. Salah satu faktor yang paling penting dalam peningkatan nilai $\mathrm{Hb}$ adalah konsumsi tablet $\mathrm{Fe}$ secara rutin dengan efek samping obat yang amis untuk mencegah terjadinya anemia saat terjadi menstruasi serta mengkonsumsi makanan yang banyak mengandung zat besi.

\section{Hubungan kepatuhan minum tablet Fe dengan kejadian anemia pada remaja putri}

Hasil analisa statistik dengan uji korelasi Spearman diperoleh nilai $p$ value $0,007(\mathrm{p}<0,05)$, artinya ada hubungan yang signifikan antara kepatuhan minum tablet $\mathrm{Fe}$ dengan kejadian anemia. Sejalan dengan penelitian yang dilakukan oleh Yuniarti, dkk (2015) menunjukkan bahwa ada hubungan secara signifikan antara kepatuhan minum tablet $\mathrm{Fe}$ dengan kejadian anemia pada remaja putri di MA Darul Imad. Kepatuhan minum tablet besi $(\mathrm{Fe})$ dipengaruhi oleh dua faktor utama, yaitu faktor dari petugas kesehatan (seperti adanya anggapan tablet besi untuk pengobatan, tindak lanjut kunjungan yang tidak baik) dan faktor dari diri individunya sendiri seperti kesadaran yang rendah akan manfaat tablet besi (Fe), adanya efek samping dari tablet besi $(\mathrm{Fe}), \quad$ kelupaan, perasaan mual/muntah (Yuniarti, dkk., 2015).

Remaja putri merupakan salah satu kelompok yang rawan menderita anemia. Oleh karena itu, sasaran program penanggulangan anemia gizi telah dikembangkan yaitu mencapai remaja putri SMP, SMA, dan sederajat, serta wanita di luar sekolah sebagai upaya strategis dalam upaya memutus simpul siklus masalah gizi. Anemia pada remaja di negara berkembang semakin meningkat dari tahun ke tahun. Perkiraan jumlah remaja di dunia usia (10-19 tahun) yang menderita anemia lebih dari satu miliar. Prevalensi anemia defisiensi besi pada anak-anak usia sekolah dan remaja putri di Amerika Serikat sebesar $8,7 \%$.

Pencegahan anemia defisiensi zat besi telah lama dilakukan di Indonesia. Salah satu pencegahannya melalui program suplementasi besi yang diberikan secara gratis. Dalam mengatasi dan melakukan pencegahan anemia dilakukan perbaikan diet secara umum dan menjaga waktu makan pagi, siang dan malam. Selain itu perlu mengkonsumsi makanan yang spesifik yang dianggap sesuai dan 
yang kaya akan vitamin seperti liver, limpa, bayam dan ekstrak buah yang berwarna merah. Pendapat lain menyatakan pendekatan untuk penanganan anemia dalam jangka pendek dapat dilakukan suplementasi besi.

$\begin{array}{rrr}\text { Sejalan } & \text { dengan } & \text { penelitian } \\ \text { Nuradiani } & (2017) & \text { tentang }\end{array}$
pengonsumsian tablet tambah darah (TTD) mingguan dan selama menstruasi menunjukkan bahwa konsumsi lebih banyak pada saat mingguan (15\%) dibandingkan selama menstruasi $(5,8 \%)$. Tingginya kepatuhan konsumsi TTD mingguan dibandingkan selama menstruasi sesuai dengan beberapa penelitian yang menunjukkan bahwa mengonsumsi TTD 1 tablet/minggu lebih dapat diterima oleh wanita dan mampu meningkatkan kepatuhan dibandingkan mengonsumsi TTD 1 tablet/hari. Rendahnya kepatuhan subjek dalam mengonsumsi TTD selama menstruasi adalah suplemen tersebut dibekalkan ke rumah sehingga pengonsumsiannya tidak dapat ditinjau secara efektif (Nuradhiani, 2017).

Hasil penelitian ini sejalan dengan penelitian yang dilakukan oleh Rusmiyawati (2015) yang menyebutkan bahwa seluruh remaja putri kelas IX dan telah diberikan tablet Fe selama 6 minggu berjumlah 49 orang. Hasil penelitian didapatkan bahwa responde yang mengalami anemia sebanyak 20 orang $(40,8 \%)$ dan sebanyak 20 orang $(40,8 \%)$ tidak patuh mengkonsumsi tablet besi 1 kali sehari selama 6 minggu. Hasil uji chi square didapatkan ada hubungan antara kepatuhan minum tablet besi dengan kejadian anemia di MA Darul Imad Kecamatan Tatah Makmur Kabupaten Banjar Tahun 2013. Perlunya meningkatkan pengetahuan remaja putri tentang anemia dan manfaat tablet $\mathrm{Fe}$ yang dibagikan agar anemia pada remaja putri dapat diatasi dengan baik (Rusmiyawati, 2015).

Peneliti berasumsi bahwa adanya hubungan ini dapat dipengaruhi oleh kepatuhan remaja dalam minum tablet Fe. Apabila remaja mengkonsumsi tablet $\mathrm{Fe}$ secara rutin maka kadar $\mathrm{Hb}$ juga akan meningkat. Sedangkan apabila kepatuhan remaja kurang dalam mengkonsumsi tablet $\mathrm{Fe}$ maka nilai $\mathrm{Hb}$ akan menurun. Dalam penelitian ini terdapat hubungan yang positif semakin bagus tingakt kepatuhan maka akan semakin baik nilai $\mathrm{Hb}$. Sehingga dapat disimpulkan bahwa tingkat kepatuhan dalam mengkonsumsi tablet $\mathrm{Fe}$ sangat berpengaruh terhadap kadar $\mathrm{Hb}$. Dalam meningkatkan kepatuhan diperlukan adanya dukungan dari orang tua, guru dan peningkatan pengetahuan tentang pentingnya konsumsi tablet Fe pada remaja.

\section{Simpulan}

Berdasarkan penelitian dan pembahasan, maka dapat diambil kesimpulan bahwa sebagian besar responden berusia 13 tahun, menstruasi pertama umur 11-12 tahun, siklus menstruasi tidak teratur dan mengkonsumsi sayuran yang mengandung zat besi, sebagian besar responden patuh dalam mengkonsumsi tablet $\mathrm{Fe}$ serta responden memiliki $\mathrm{Hb}$ yang normal, sehingga ada hubungan yang signifikan antara kepatuhan minum tablet $\mathrm{Fe}$ dengan kejadian anemia. Sehingga diharapkan penelitian lebih lanjut tentang pengaruh penyuluhan dengan cara yang modern dan memanfaatkan teknologi terhadap kepatuhan dan nilai Hb. Serta menilai pengetahuan responden sebelum dilakukan penyuluhan 


\section{Daftar Pustaka}

Arisman. Pengaruh anemia pada remaja putri pada pondok pesantren di Cirebon, Jurnal : 2010. Vol. 2. 2010

Cahyaningtyas, Dwi Kartika. Pengaruh Konsumsi Tablet Fe Terhadap Peningkatan Kadar Hemoglobin Pada Remaja Putri di SMAN 2 Ngaglik Kabupaten. Publikasi Penelitian 2017

Departemen Kesehatan RI. Program Penanggulangan Anemia Gizi Pada Wanita UsiaSubur (WUS) dan Remaja Putri. Jakarta: Direktorat Gizi Masyarakat. 2012

Dieny, Fillah. Permasalahan Gizi Pada Remaja Putri. Yogyakarta: Graha Ilmu.2014.

Dinas Kesehatan Kabupaten Bondowoso. Daftar penyakit tahun 2018. Bondowoso, Dinkes Bondowoso. 2018

Dumilah, Pratiwi dan Sri Utami. Hubungan Kejadian Anemia Dengan Prestasi Belajar Siswi Di SMP Unggulan Bina Insani. Jurnal Online. DOI: 10.2473/amnt.v1i4.2017.331340.2017 .

Giyanti, fitri. 2016. Pengaruh Pemberian Tablet Fe Terhadap Kenaikan Kadar Hemoglobin Remaja Putri Dengan Anemia Di SMK Negeri I Ponjong Gunungkidul. Naskah

Publikasi. 2016

Hidayat N, Sunarti S. Validitas Pemeriksaan Kadar Hemoglobin Menggunakan Metode $\mathrm{Hb}$ Meter pada Remaja Putri di MAN
Wonosari. Kesmas Vol.9(1):1118. 2015

Kementrian Kesehatan RI. Hasil Riset Kesehatan Dasar, dalam www.depkes.go.id.2013

Kristianti, Hubungan Anemia dengan Siklus Menstruasi pada Remaja Putri di SMA Negeri 1 Imogiri, Bantul, Yogyakarta Tahun 2013, Jurnal Studi Pemuda. Vol. 3, No. 1, Mei 2014

Krummer, Debra L, Kris Etherton, 2006. Nutrition in women health, an Aspen Publications . Aspen Publisher Inc. Gaitherburtg Maryland

Maisa, Esthika A., dkk. Hubungan antara Dukungan Keluarga dengan Kepatuhan Konsumsi Tablet Fe pada Ibu Hamil di Wilayah Kerja Puskesmas Nanggalo Kecamatan Nanggalo. Publikasi Penelitian. 2015.

Nuradhiani, Annisa, dkk. Dukungan Guru Meningkatkan Kepatuhan Konsumsi Tablet Tambah Darah Pada Remaja Putri Di Kota Bogor. Jurnal Penelitian. Volume 12, Nomor 3, November 2017.

Proverawati, A dan Wati, E K. Imu Gizi untuk Perawat dan Gizi Kesehatan. Yulia Medika: Yogyakarta. 2011

Pradanti, dkk. Hubungan Asupan Zat Besi (Fe) dan Vitamin C dengan Kadar Hemoglobin pada Siswi Kelas VIII SMP Negeri 3 Brebes. Vol. 4, No. 1. Jurnal Gizi Universitas Muhammadiyah Semarang. 2015 
Rahmawati F, Subagio HW. Kepatuhan konsumsi tablet besi folat pada ibu hamil dan faktor yang memengaruhi. Journal of Nutrition College 1(1):55-62. 2012

Retno Fitrianingtyas. Usia menarche, status gizi, dan siklus menstruasi santri putri. Jurnal preventia. Vol.2 2017.

Rusmiyawati, Hubungan antara Kepatuhan Minum Tablet $\mathrm{Fe}$ dengan Kejadian Anemia pada Remaja Putri di MA Darul Imad Kecamatan Tatah Makmur Kabupaten Banjar. Jurnal Publikasi Kesehatan Masyarakat Indonesia, Vol. 2 No.1, April 2015.

Sani Ruben. 2010. Penyakit Yang Harus Di Waspadai Wanita Di Lengkapi Dengan Cara Penanggulangan dan Pencegahan, Getar Hati, Yogyakarta. Publikasi Penelitian.2010.

Susanti Y, Briawan D, Martianto D. Suplementasi besi mingguan meningkatkan hemoglobin sama efektif dengan kombinasi mingguan dan harian pada remaja putri. J Gizi Pangan 13(1):27-34. 2016

Wahyuningsih, A. Hubungan Kadar Hemoglobin Dengan Keteraturan Siklus Menstruasi Pada Mahasiswi Prodi D III Kebidanan Tingkat III Stikes Muhammadiyah Klaten, Jurnal Involusi Kebidanan, Vol. 2, No. 3, Januari 2012, 34-45. 2012

Yuniarti, dkk. Hubungan antara kepatuhan minum tablet $\mathrm{Fe}$ dengan kejadian anemia pada remaja Putri di MA Darul Imad Kecamatan Tatah Makmur Kabupaten Banjar Tahun 2013.
Jurnal Publikasi. Vol. 2 No. 1, April 2015. 